Provided for non-commercial research and education use. Not for reproduction, distribution or commercial use.

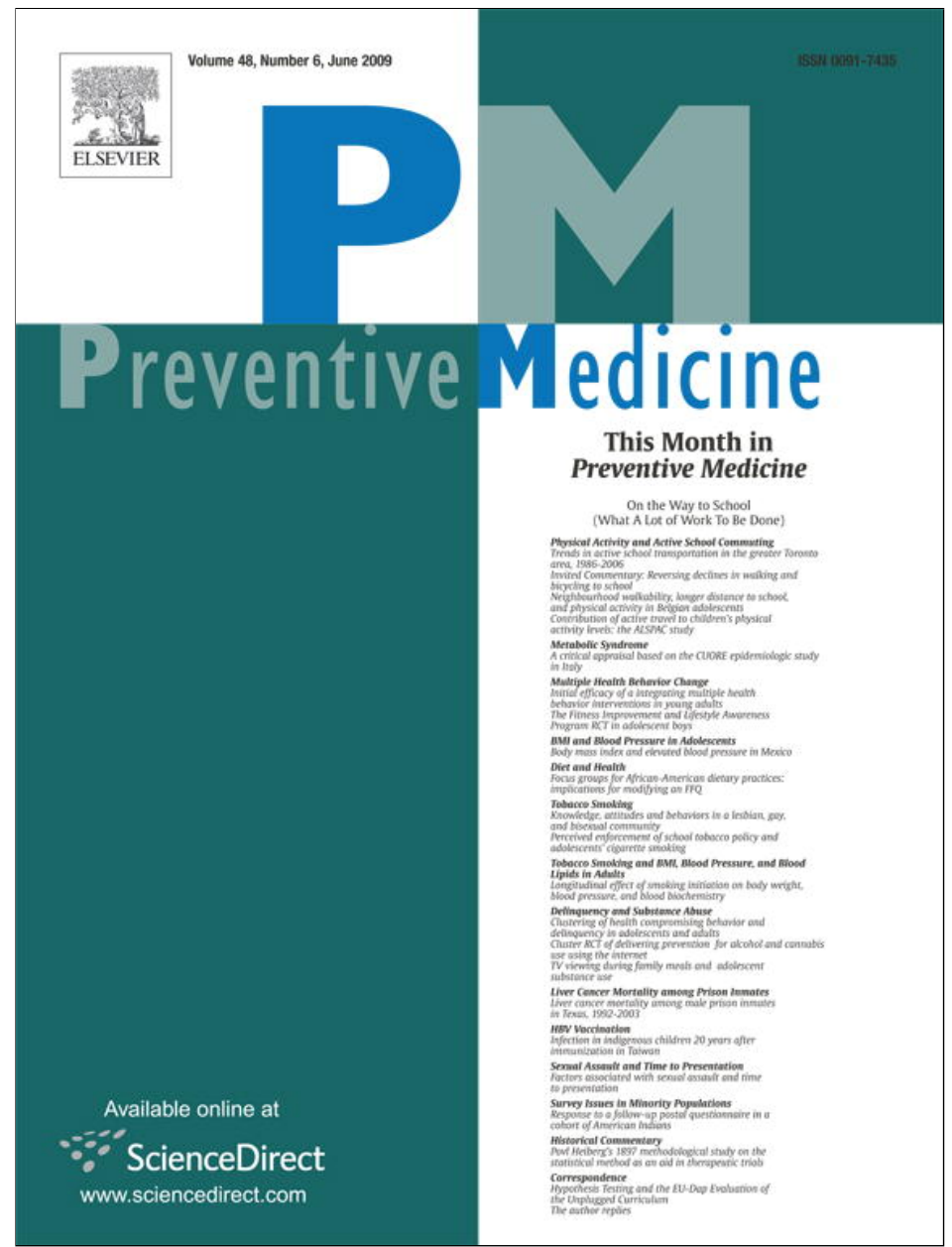

This article appeared in a journal published by Elsevier. The attached copy is furnished to the author for internal non-commercial research and education use, including for instruction at the authors institution and sharing with colleagues.

Other uses, including reproduction and distribution, or selling or licensing copies, or posting to personal, institutional or third party websites are prohibited.

In most cases authors are permitted to post their version of the article (e.g. in Word or Tex form) to their personal website or institutional repository. Authors requiring further information regarding Elsevier's archiving and manuscript policies are encouraged to visit:

http://www.elsevier.com/copyright 


\title{
Lower neighbourhood walkability and longer distance to school are related to physical activity in Belgian adolescents
}

\author{
Delfien Van Dyck ${ }^{\mathrm{a}, \mathrm{b}, *}$, Greet Cardon ${ }^{\mathrm{b}}$, Benedicte Deforche ${ }^{\mathrm{a}, \mathrm{c}}$, Ilse De Bourdeaudhuij ${ }^{\mathrm{b}}$ \\ a Fund for Scientific Research Flanders (FWO), Belgium \\ ${ }^{\mathrm{b}}$ Ghent University, Department of Movement and Sports Sciences, Belgium \\ ${ }^{c}$ Vrije Universiteit Brussels, Department of Human Biometrics and Biomechanics, Belgium
}

\section{A R T I C L E I N F O}

Available online 11 March 2009

\section{Keywords:}

Adolescents

Physical activity

Walkability

Active transport

Distance to school

\section{A B S T R A C T}

Objective. To investigate whether adolescents living in a high-walkable town centre are more physically active than those living in a less-walkable suburb.

Methods. This cross-sectional study was conducted in Izegem (Belgium). Data collection took place in spring 2007. One high-walkable urban neighbourhood and one less-walkable suburban neighbourhood were selected, based on objective connectivity and residential density. One hundred twenty adolescents (12-18 years, 60 per neighbourhood) completed the Neighbourhood Environmental Walkability Scale (NEWS), the Neighbourhood Physical Activity Questionnaire (NPAQ), wore a pedometer for 7 days and filled in an activity log.

Results. In contrast with the expectations, adolescents living in the less-walkable suburb reported $220 \mathrm{~min} /$ week more cycling for transport than those living in the high-walkable town centre. A trend towards significance was found for mean step counts/day with 1371 more steps/day for suburban adolescents. Travel time to school was 7.4 min less for urban adolescents.

Conclusions. In contrast with previous results in adults, lower walkability and larger distance to school was associated with more physical activity in Belgian adolescents. Therefore, physical environmental interventions designed for adults, focusing on increases in connectivity, residential density and connectivity, might not be effective for Belgian adolescents.

(c) 2009 Elsevier Inc. All rights reserved.

\section{Introduction}

Adolescence is a period of steep decline in physical activity (PA) levels with considerable proportions of American and European adolescents not meeting the PA guideline of 60 min moderate to vigorous PA daily (Pate et al., 2002). Ecological models state that multiple interventions are needed to increase PA, with attention to demographic, psychosocial and physical environmental factors (Sallis and Owen, 2002). In adults, associations between the physical environment and PA have been well established (Sallis and Owen, 2002), but in adolescents, only a few studies have investigated these associations and results are ambiguous (Panter et al., 2008). Distance to school appears to be a consistent predictor of adolescents' travel behaviour, with those who have shorter journey distances being more likely to walk or cycle to school (Nelson et al., 2008). However, mixed results were found concerning the relation between walkability parameters and adolescents' PA behaviour (Panter et al., 2008). A

\footnotetext{
* Corresponding author. Ghent University, Faculty of Medicine and Health Sciences, Department of Movement and Sports Sciences, Watersportlaan 2, B-9000 Ghent Belgium. Fax: +329264 6484 .

E-mail address: Delfien.VanDyck@UGent.be (D. Van Dyck).
}

possible explanation for these mixed findings, is that not only the neighbourhood, but also the home and school environment are important in explaining adolescents' PA behaviour (Van Sluijs et al., 2007).

Because of the indistinctness in the current literature on adolescents and the clear link between walkability and PA in adults in the United States (Sallis and Owen, 2002), Australia (Owen et al., 2007) and Europe (De Bourdeaudhuij et al., 2003; Van Dyck et al., 2009), the main aim of the present study was to investigate whether this association also exists in adolescents. Therefore, we hypothesized that adolescents living in a high-walkable town centre are more physically active than adolescents living in a less-walkable suburb.

\section{Methods}

Participants and procedures

The study was conducted in Izegem (26,544 inhabitants), a town in West-Flanders, Belgium. Data collection took place between February and April 2007. Two neighbourhoods were selected, based on objective geographical map data of connectivity and residential density. These two parameters are frequently used to measure neighbourhood walkability (Leslie et al., 2007). Key elements of 'walkability' are residential density, connectivity and land use mix. One high-walkable neighbourhood with high connectivity and high residential density, located in the town centre, and one less- 


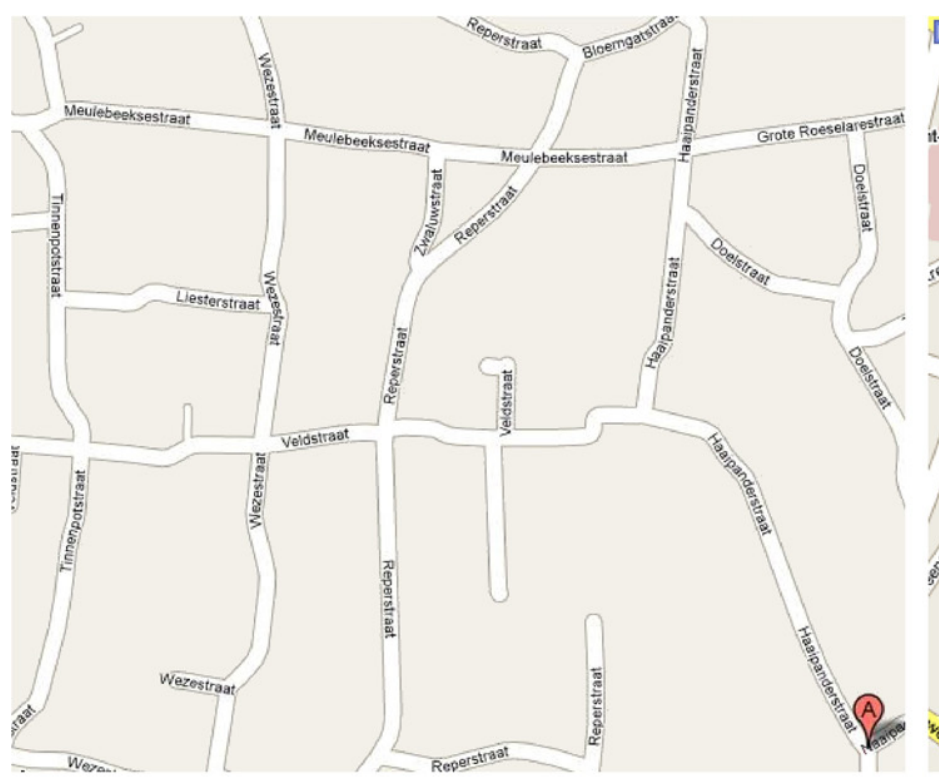

Suburban neighbourhood

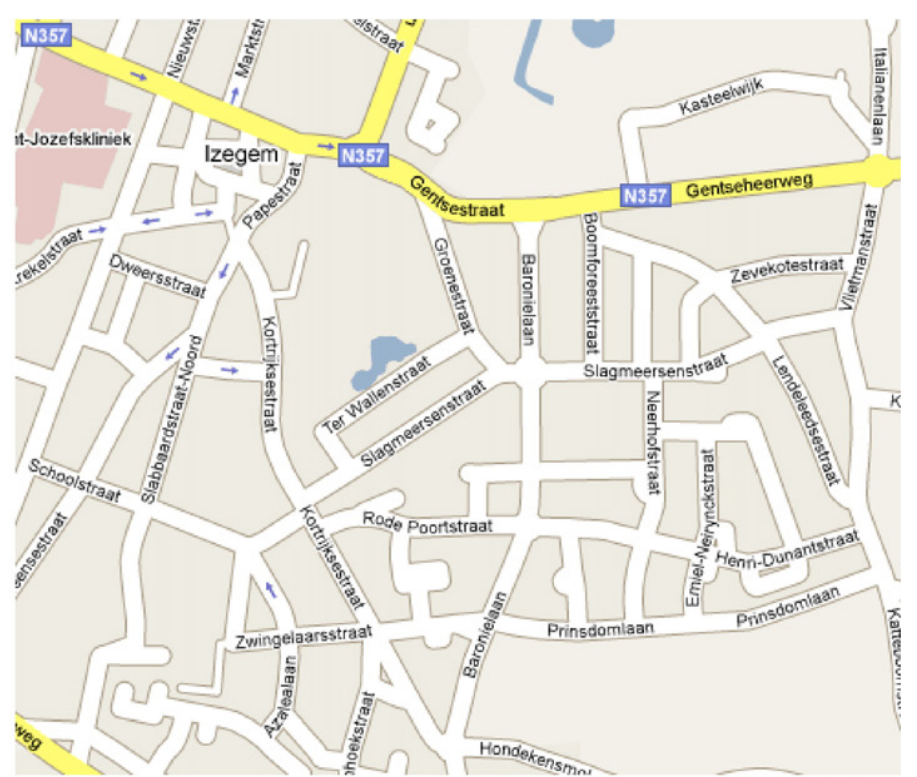

Urban neighbourhood (town centre)

Fig. 1. Map image of the high-walkable urban and less-walkable suburban neighbourhood. Location of the study: Izegem, Belgium. Date of the study: 2007. Data analysis: 2008. Study population: 120 adolescents (12-18 years): $39.2 \%$ boys, $14.9 \pm 2.0$ years, $20.0 \pm 2.7 \mathrm{~kg} / \mathrm{m}^{2}$.

walkable neighbourhood with low connectivity and low residential density, located in the suburbs, were selected. Both neighbourhoods contained approximately 1500 inhabitants, but due to its lower density, the physical size of the suburban neighbourhood was larger. Fig. 1 shows a map of both neighbourhoods.

The local government provided an address list of all adolescents living in both neighbourhoods. In each neighbourhood, 120 randomly selected adolescents received a letter with information on the study. Two to 6 days after posting the letters, possible participants were visited at home. Adolescents (12-18 years) who agreed to participate, were asked to fill out a written informed consent form. Also passive consent from the adolescents' parents was obtained. During the home visit, a pedometer, activity log and questionnaire were delivered. The pedometer was worn for seven consecutive days. After 1 week, everything was recollected during a second home visit. Home visits were ended when 60 participants were found in each neighbourhood. In the high-walkable neighbourhood, 102 homes needed to be approached to recruit 60 participants; in the less-walkable neighbourhood, 104 homes were visited. A sample of 120 adolescents (47 boys, 73 girls, $14.9 \pm 2.0$ years, $20.0 \pm 2.7 \mathrm{~kg} / \mathrm{m}^{2}$ ) participated in the study. Analyses on gender, age, BMI, parental education level and parental working situation showed no significant differences between participants of both neighbourhoods.

\section{Instruments}

Objective PA data were collected using the Yamax Digiwalker SW-200 pedometer. Participants wore the pedometer for seven consecutive days and completed an activity $\log$ at the end of each day they wore the pedometer. For every minute of cycling or swimming reported, 150 steps were imputed to the daily number of steps (Miller et al., 2006). Participants were also asked to fill in an adjusted version of the Neighbourhood Physical Activity Questionnaire (NPAQ) (Giles-Corti et al., 2006) and the Flemish Neighbourhood Environmental Walkability Scale (NEWS) (De Bourdeaudhuij et al., 2003). In the NEWS, perceptions of physical environmental features in the neighbourhood, like connectivity, residential density, and land use mix are assessed. Moreover, information on sports participation was collected, using the sports index of the Flemish Physical Activity Questionnaire (FPAQ) (Philippaerts et al., 2006).

Data analysis

All data analyses were conducted using SPSS 15.0 for Windows. Independent sample $t$-tests were used to analyse differences in neighbourhood perceptions, PA behaviour, and distance to school between urban and suburban adolescents. Statistical significance was set at a level of .05 .

\section{Results}

Differences in neighbourhood perceptions, PA and travel time to school between the neighbourhoods (Table 1)

Results of the NEWS showed that urban adolescents perceived higher connectivity $(p=.007)$, better land use mix $(p<.001)$ and higher residential density $(p<.001)$ than suburban adolescents, so the town centre was perceived as a more walkable area than the suburb was. These findings support the objective measurement of neighbourhood walkability, for which geographical map data of residential density and connectivity were used.

Table 1

Differences in neighbourhood perceptions, physical activity and school distance between town centre and suburb.

\begin{tabular}{|c|c|c|c|}
\hline & $\begin{array}{l}\text { High walkable } \\
\text { city centre }\end{array}$ & $\begin{array}{l}\text { Less walkable } \\
\text { suburb }\end{array}$ & $t(p)$ \\
\hline & Mean (SD) & Mean (SD) & \\
\hline $\begin{array}{l}\text { Residential density } \\
1=\text { low, } 3=\text { high }\end{array}$ & $2.27(.53)$ & $1.64(.40)$ & $7.36(* * *)$ \\
\hline $\begin{array}{l}\text { Connectivity } \\
1=\text { low, } 4=\text { high }\end{array}$ & $3.18(.59)$ & $2.89(.55)$ & $2.75(* *)$ \\
\hline \multicolumn{4}{|c|}{ Land use mix access (perceived distance to facilities by bike) } \\
\hline \multicolumn{4}{|c|}{$1=1-5 \mathrm{~min}, 2=6-10 \mathrm{~min}, 3=11-20 \mathrm{~min}, 4=21-30 \mathrm{~min}, 5=>30 \mathrm{~min}$} \\
\hline & $2.36(.44)$ & $3.40(.61)$ & $10.75(* * *)$ \\
\hline $\begin{array}{l}\text { Distance to school } \\
\text { (minutes) }\end{array}$ & $7.4(5.9)$ & $13.6(3.5)$ & $6.21(* * *)$ \\
\hline Steps/day & $12,055(3671)$ & $13,426(4062)$ & $1.94(.055)$ \\
\hline $\begin{array}{l}\text { Cycling for transport } \\
\text { (min/week) }\end{array}$ & $126.32(107.14)$ & $244.31(164.66)$ & $3.00(* *)$ \\
\hline To school & $49.68(60.63)$ & $107.59(63.64)$ & $5.11(* * *)$ \\
\hline To other destinations & $76.65(87.19)$ & $136.72(271.04)$ & 1.61 \\
\hline $\begin{array}{l}\text { Walking for transport } \\
\text { (min/week) }\end{array}$ & $50.27(78.61)$ & $27.95(113.08)$ & 1.26 \\
\hline To school & $8.55(30.02)$ & $2.59(19.70)$ & 1.29 \\
\hline To other destinations & $41.73(65.57)$ & $25.36(111.48)$ & .99 \\
\hline $\begin{array}{l}\text { Cycling for recreation } \\
\text { (min/week) }\end{array}$ & $9.03(26.14)$ & $22.50(55.68)$ & 1.68 \\
\hline $\begin{array}{l}\text { Walking for recreation } \\
\text { (min/week) }\end{array}$ & 41.94 (104.99) & $22.24(63.32)$ & 1.25 \\
\hline $\begin{array}{l}\text { Sports participation } \\
\text { (min/week) }\end{array}$ & $215.65(224.81)$ & $156.90(130.12)$ & 1.77 \\
\hline
\end{tabular}

Location of the study: Izegem, Belgium.

Date of the study: 2007.

Data analysis: 2008

Study population: 120 adolescents (12-18 years): $39.2 \%$ boys, $14.9 \pm 2.0$ years, $20.0 \pm$ $2.7 \mathrm{~kg} / \mathrm{m}^{2}$.

$* p \leq .05$

** $p \leq .01$.

$* * * \quad p \leq .001$. 
In contrast with the expectations, adolescents living in the lesswalkable suburb reported on average $220 \mathrm{~min} /$ week more cycling for transport than those living in the high-walkable town centre $(p=.004)$. Suburban adolescents cycled $57 \mathrm{~min} /$ week more to school than urban adolescents $(p<.001)$, while cycling for transport to other destinations (shops, friends, hobbies), did not differ significantly between the two neighbourhoods.

Also unexpected, a trend towards significance $(p=.055)$ was found for mean step counts/day. Suburban adolescents took on average 1371 more steps/day than urban adolescents.

For the urban adolescents who commuted to school through active transportation ( $79 \%$ of the sample; $12,9 \%$ walking, $66.1 \%$ cycling), travel time to school was on average 7.4 (5.9) minutes less than for the suburban adolescents commuting to school through active transportation ( $81 \%$ of the sample; $1.7 \%$ walking, $79.3 \%$ cycling) $(p<.001)$ (Table 1$)$.

\section{Discussion and conclusions}

The main finding of this study was that living in a less-walkable neighbourhood was associated with more PA (more cycling for transport and a trend towards more steps/day). This result is opposite to the results found for adults in international and Belgian studies (Sallis and Owen, 2002; De Bourdeaudhuij et al., 2003, Van Dyck et al., 2009), showing consistently that adults living in a high-walkable neighbourhood are more physically active.

The difference in cycling for transport can possibly be explained by a difference in distance to school. Both in the town centre and the suburb, a similar percentage of adolescents commute actively to school, but the covered distance is larger for suburban adolescents. This larger distance to school is a logical consequence of the lower connectivity and lower land use mix in the suburb, both characteristics of less walkability. However, the positive association between less walkability, a larger distance to school and more cycling for transport does not accord with the literature, where a shorter distance to school is consistently associated with more active transportation (Nelson et al., 2008). A possible explanation for these different results could be that Belgian adolescents generally have a positive attitude towards cycling, they cycle for transportation as long as the distance is feasible. Also, 'walkability' is a relative concept. Although significant differences in walkability between the two neighbourhoods were found, both urban and suburban areas are relatively high-walkable in Belgium, with schools being within a 'bikable' distance. Therefore, adolescents have the possibility to cycle for transport both urban and suburban areas. However, when comparing the present results to findings of environmental studies in Belgian adults living in similar neighbourhoods, large differences in the associations between walkability and PA exist. In adults, living in a less-walkable neighbourhood is consistently related to less walking and cycling for transport, although distances to different facilities are often feasible for active commuting (Van Dyck et al., 2009). This suggests that the associations between neighbourhood walkability and PA are different for Belgian adolescents than for Belgian adults, which is important for the development of future environmental interventions.

A possible explanation for the trend towards more steps per day for the suburban adolescents, is that also the time spent in cycling to school and to other destinations was included in the mean step counts per day.

Although the results were insignificant (possibly due to a lack of power caused by the small sample size), living in the high-walkable neighbourhood was associated with $60 \mathrm{~min} /$ week more sports activities. Because no environmental information on sports facilities was collected, this finding can not be explained properly. However, as sports participation was also included in the total number of steps, a strong impact of cycling behaviour on the total step counts can be presumed because mean step counts were higher in the less-walkable neighbourhood.

Strengths of the present study include the use of both objective and subjective PA measurements and the comparability of both groups for demographic parameters. Also, PA levels of the study sample were representative for the Belgian adolescent population. Limitations are the small study sample, cross-sectional character and limited generalisability of the results, because the study was conducted in one town and only two neighbourhoods were included. Moreover, differences between the urban and suburban samples can exist, although possible participants were randomly selected.

The results of this study suggest that physical environmental interventions designed for adults, in which efforts are made to increase connectivity, residential density and land use mix, might not be as effective for suburban adolescents, at least not for Belgian adolescents. However, in younger children, these interventions could be effective because parental perceptions on neighbourhood walkability (e.g. traffic safety, crime safety, connectivity) are crucial in the decision about a child's travel mode (Panter et al., 2008).

Conflict of interest statement

The authors declare that there are no conflicts of interest.

\section{Acknowledgments}

This research was supported by Fund for Scientific Research Flanders (FWO) B/09731/01. The authors acknowledge Lic. I. Quaegebeur for data collection.

\section{References}

De Bourdeaudhuij, I., Sallis, J.F., Saelens, B.E., 2003. Environmental correlates of physical activity in a sample of Belgian adults. Am. J. Health Promot. 18, 83-92.

Giles-Corti, B., Timperio, A., Cutt, H., et al., 2006. Development of a reliable measure of walking within and outside the local neighbourhood: RESIDE's Neighbourhood Physical Activity Questionnaire. Prev. Med. 42, 455-459.

Panter, J.R., Jones, A.P., Van Sluijs, E., 2008. Environmental determinants of active trave in youth: a review and framework for future research. Int. J. Behav. Nutr. Phys. Act. 5,34

Pate, R., Freedson, P., Sallis, J., et al., 2002. Compliance with physical activity guidelines: prevalence in a population of children and youth. Ann. Epidemiol. 12, 303-308.

Philippaerts, R., Matton, L., Wijndaele, K., et al., 2006. Validity of a physical activity questionnaire in 12- to 18-year-old boys and girls. Int. J. Sports Med. 27, 131-136.

Leslie, E., Coffee, N., Frank, L., Owen, N., Bauman, A., Hugo, G., 2007. Walkability of local communities: using Geographic Information Systems to objectively assess relevant environmental attributes. Health Place 13, 111-122.

Miller, R., Brown, W. Tudor-Locke, C. 2006. But what about swimming and cycling? How to count non-ambulatory activity when using pedometers to assess physical activity. J. Phys. Act Health 3, 257-266.

Nelson, N.M., Foley, E., O'Gorman, D.J., Moyna, N.M., Woods, C.B., 2008. Active commuting to school: how far is too far? Int. J. Behav. Nutr. Phys. Act 5, 1.

Owen, N., Cerin, E., Leslie, E., et al., 2007. Neighbourhood walkability and the walking behaviour of Australian adults. Am. J. Prev. Med. 33, 387-395.

Sallis, J., Owen, N., 2002. Ecological models of health behaviour. In: Glanz, K, Rimer, B Lewis, M (Eds.), Health Behaviour and Health Education: Theory, Research and Practice. Jossey-Bass, San Francisco, pp. 462-484.

Van Dyck, D., Deforche, B., Cardon, G., De Bourdeaudhuij, I., 2009. Neighbourhood walkability and its particular importance for adults with a preference for passive transport. Health Place 15, 496-504.

Van Sluijs, E.M.F., McMinn, A.M., Griffin, S.J., 2007. Effectiveness of interventions to promote physical activity in children and adolescents: systematic review of controlled trials. BMJ 335, 703. 